\title{
Alcohol Decreases Baseline Brain Glucose Metabolism More in Heavy Drinkers Than Controls But Has No Effect on Stimulation-Induced Metabolic Increases
}

\author{
Nora D. Volkow, ${ }^{1}$ Gene-Jack Wang, ${ }^{1}$ Ehsan Shokri Kojori, ${ }^{1}$ Joanna S. Fowler, ${ }^{2}{ }^{\circ}$ Helene Benveniste, ${ }^{3}$ and Dardo Tomasi $^{1}$ \\ ${ }^{1}$ National Institute on Alcohol Abuse and Alcoholism, Bethesda, Maryland 20892, ${ }^{2 B i o s c i e n c e s ~ D e p a r t m e n t, ~ B r o o k h a v e n ~ N a t i o n a l ~ L a b o r a t o r y, ~ U p t o n, ~ N e w ~}$ \\ York 11973-5000, and 32Department of Anesthesiology, Stony Brook Medicine, Stony Brook, New York 11794
}

\begin{abstract}
During alcohol intoxication, the human brain increases metabolism of acetate and decreases metabolism of glucose as energy substrate. Here we hypothesized that chronic heavy drinking facilitates this energy substrate shift both for baseline and stimulation conditions. To test this hypothesis, we compared the effects of alcohol intoxication $(0.75 \mathrm{~g} / \mathrm{kg}$ alcohol vs placebo) on brain glucose metabolism during video stimulation (VS) versus when given with no stimulation (NS), in 25 heavy drinkers (HDs) and 23 healthy controls, each of whom underwent four PET- ${ }^{18}$ FDG scans. We showed that resting whole-brain glucose metabolism (placebo-NS) was lower in HD than controls $(13 \%, p=0.04)$; that alcohol (compared with placebo) decreased metabolism more in HD $(20 \pm 13 \%)$ than controls $(9 \pm 11 \%, p=0.005)$ and in proportion to daily alcohol consumption $(r=0.36, p=0.01)$ but found that alcohol did not reduce the metabolic increases in visual cortex from VS in either group. Instead, VS reduced alcohol-induced decreases in whole-brain glucose metabolism (10 $\pm 12 \%)$ compared with NS in both groups $(15 \pm 13 \%, p=0.04)$, consistent with stimulation-related glucose metabolism enhancement. These findings corroborate our hypothesis that heavy alcohol consumption facilitates use of alternative energy substrates (i.e., acetate) for resting activity during intoxication, which might persist through early sobriety, but indicate that glucose is still favored as energy substrate during brain stimulation. Our findings are consistent with reduced reliance on glucose as the main energy substrate for resting brain metabolism during intoxication (presumably shifting to acetate or other ketones) and a priming of this shift in HDs, which might make them vulnerable to energy deficits during withdrawal.
\end{abstract}

Key words: acetate metabolism; alcoholism; glial metabolism; glycolysis; positron emission tomography

\section{Introduction}

Among substances of abuse, alcohol is the one most widely consumed. It is estimated that $56 \%$ of Americans 18 years or older consume alcohol at least once a month (SAMHSA, 2012a). Although the majority of individuals use alcohol in moderation, it is estimated that $7.1 \%$ are heavy drinkers (HDs; 5 or more drinks/d on at least 5 different days in the past 30 d) (SAMHSA, 2012b). Thus, understanding the effects that heavy alcohol drinking has on the human brain is crucial for developing interventions to minimize potential adverse effects.

Brain imaging studies have shown that acute alcohol administration decreases glucose utilization by the resting human brain, which was originally interpreted to reflect decreases in brain activity (Volkow et al., 1990; de Wit et al., 1990; Wang et al., 2000;

Received Nov. 30, 2014; revised Dec. 29, 2014; accepted Jan. 13, 2015.

Author contributions: N.D.V., G.-J.W., J.S.F., and H.B. designed research; G.-J.W., J.S.F., H.B., and D.T. performed research; N.D.V., J.S.F., H.B., and D.T. analyzed data; N.D.V. wrote the paper.

This work was supported by the National Institutes of Health Intramural Research Program. We thank Christopher Wong, Dave Alexoff, Colleen Shea, Pauline Carter, Karen Torres Apelskog, and Ruben Baler for their contributions.

The authors declare no competing financial interests.

Correspondence should be addressed to Dr. Nora D. Volkow, National Institute on Drug Abuse, National Institutes of Health, 6001 Executive Boulevard, Room 5274, Bethesda, MD 20892. E-mail: nvolkow@nida.nih.gov.

DOI:10.1523/JNEUROSCI.4877-14.2015

Copyright $\odot 2015$ the authors $\quad 0270-6474 / 15 / 353248-08 \$ 15.00 / 0$
Schreckenberger et al., 2004). However, subsequent studies showed that even low doses of alcohol, with minimal behavioral effects, significantly decreased baseline brain glucose metabolism (Volkow et al., 2006). Moreover, alcohol-induced reductions in brain glucose metabolism were larger than those induced by doses of lorazepam that resulted in greater sedation (Volkow et al., 1993). This prompted the hypothesis that, during alcohol intoxication, the brain increases its metabolism of the alcohol metabolite acetate while decreasing glucose metabolism. Specifically, acetate, which serves as an energy substrate for astrocytes (Cruz et al., 2005), is readily taken up into the brain; and although its concentration in blood is normally low, it rises significantly during alcohol intoxication (Waniewski and Martin, 1998). Indeed, using PET and $\left[{ }^{11} \mathrm{C}\right]$ acetate, we recently showed that, during alcohol intoxication, the brain increased the metabolism of acetate and decreased the metabolism of glucose (Volkow et al., 2013). We also reported that HDs compared with controls showed a trend for an increase in brain acetate metabolism, although no difference in alcohol induced increases in acetate metabolism (Volkow et al., 2013). Similarly, a recent magnetic resonance spectroscopy (MRS) study also reported greater acetate metabolism in the occipital cortex for HDs studied during sobriety than for controls (Jiang et al., 2013), suggesting a shift to acetate metabolism in HDs that might persist beyond the intox- 
ication state. Here, we test the hypothesis that repeated heavy alcohol use is associated with a decrease in the brain's reliance on glucose as the main fuel both for baseline (rest) and for sensory stimulation conditions.

For this purpose, we used PET and ${ }^{18} \mathrm{FDG}$ to evaluate the effects of alcohol intoxication $(0.75 \mathrm{~g} / \mathrm{kg}$ alcohol compared with placebo) and video stimulation (VS; compared with no stimulation [NS]), on brain glucose metabolism in a cohort of $25 \mathrm{HDs}$ and 23 healthy normal controls (NMLs), each of whom underwent four randomized PET- ${ }^{18}$ FDG scans (placebo-NS, alcoholNS, placebo-VS, alcohol-VS). We hypothesized the following: (1) alcohol-related decreases in glucose metabolism would be larger for HD than for NML and associated with alcohol consumption history; and (2) during alcohol intoxication, the metabolic increases in visual cortex from VS would be similarly attenuated due to a shift to alternative brain energy substrates (presumably acetate or other ketone bodies).

\section{Materials and Methods}

Subjects. The effects of acute alcohol administration $(0.75 \mathrm{~g} / \mathrm{kg})$ on brain glucose metabolism were measured in 23 healthy controls ( $33 \pm 7$ years of age; 12 males, 11 females; $14 \pm 2$ years of education) and 25 heavy alcohol drinkers ( $33 \pm 9$ years of age; 25 males; $13 \pm 2$ years of education) using PET and ${ }^{18} \mathrm{FDG}$ both with (VS) and without (NS) visual/auditory stimulation (watching a video vs watching a blank screen). The NML participants had to have prior experience with alcohol but should not drink $>1$ drink/d. Inclusion criteria for HDs was 4 (5) or more drinks/d if female (male) at least on 3 or more occasions per week. The HDs reported their last use of alcohol was within $3 \mathrm{~d}$ of the PET scans. Fifteen of the 23 healthy controls, but none of the HDs, were included as participants in the study that assessed the effects of alcohol intoxication on brain glucose metabolism to be compared with its effects on brain $\left[{ }^{11} \mathrm{C}\right]$ acetate uptake (Volkow et al., 2013).

Alcohol and placebo administration and stimulation conditions. Participants were tested over a $4 \mathrm{~d}$ period, with placebo on $2 \mathrm{~d}$ (once with NS and once with VS) and with alcohol on the other $2 \mathrm{~d}$ (once with NS and once with VS). The order of drug and stimulation conditions was randomly assigned across subjects to control for order effects. Subjects drank the alcohol $(0.75 \mathrm{~g} / \mathrm{kg}$ mixed in a caffeine-free diet soda) or the placebo (caffeine-free diet soda) beverages within a $20 \mathrm{~min}$ period under blind conditions. For this purpose, we used a specialized drinking container with an alcohol-containing lid that provided the smell of alcohol and delivered the same volume of liquid for both conditions. Participants were injected with ${ }^{18} \mathrm{FDG} 40 \mathrm{~min}$ after drinking onset (20 min after completion of drinking). This timing was selected to match the time for alcohol concentration to peak in the human brain after oral alcohol consumption (Hetherington et al., 1999). We used a $0.75 \mathrm{~g} / \mathrm{kg}$ oral alcohol dose, which is approximately equivalent to three drinks for a $50 \mathrm{~kg}$ person and is within the range consumed by social drinkers (Stinson et al., 1998).

For the NS condition, participants watched a blank computer screen; whereas for the VS condition, they watched a video that contained peaceful scenes showing normal people doing recreational activities (i.e., horseback riding, running in the park) that included the corresponding soundtracks (background noise but no conversations). Participants were exposed to the blank screen or the video starting at the time of ${ }^{18} \mathrm{FDG}$ injection and continued throughout the first $30 \mathrm{~min}$ of the ${ }^{18} \mathrm{FDG}$ uptake period while they rested comfortably in a quiet room. Participants were asked to keep their eyes open at all times to ensure they did not fall asleep during the procedures, and a nurse remained by their side to ensure compliance. Thirty minutes after ${ }^{18} \mathrm{FDG}$ injections, participants were positioned in the PET scanner for scanning.

Behavioral evaluation and measures of alcohol in plasma. Before placebo or alcohol, and at 10,15, 30, and $85 \mathrm{~min}$ after placebo or alcohol administration, subjects were asked to evaluate their subjective sense of "high" and at 15 and $100 \mathrm{~min}$ their sense of intoxication and desire for alcohol on analog scales (rated 1-10).
Blood alcohol concentration levels were measured before and 20, 40, 50,80 , and $100 \mathrm{~min}$ after the initiation of alcohol administration using the enzymatic assay described by Lloyd et al. (1978).

PET scans. Each participant underwent four PET- ${ }^{18}$ FDG scans done on separate days with the order of scans randomized: placebo-NS, placebo-VS, alcohol-NS, and alcohol-VS. Scans were done using a Siemens ECAT EXACT HR + tomograph. Participants were positioned in the scanner using their individual head holder. Transmission scans were obtained using germanium-68 to correct for attenuation. For the emission scans, participants were injected with $4-6 \mathrm{mCi}$ of ${ }^{18} \mathrm{FDG}$, and a 20 min emission scan was started $35 \mathrm{~min}$ after injections. Images were reconstructed using filtered back projection (Hann filter with a $4.9 \mathrm{~mm}$ Kernel FWHM). The ${ }^{18} \mathrm{FDG}$ scans were transformed into metabolic images as previously described (Volkow et al., 1990), and metabolic rates were computed using an extension of the Sokoloff s model (Phelps et al., 1979).

To ensure that subjects did not fall asleep, they were monitored throughout the procedure and were asked to keep their eyes open. Subjects were scanned in a dimly lit room with noise kept to a minimum, and the only intervention was the periodic assessment of the effects of alcohol or placebo.

Analysis. Statistical parametric mapping (SPM8; Wellcome Trust Centre for Neuroimaging, London) (Friston et al., 1995) was used for the analysis. Gender and smoking status were entered as covariates to control for differences between the groups on these variables.

The absolute metabolic images were spatially normalized to the stereotactic space of the $\mathrm{MNI}$ and resliced to $2 \mathrm{~mm}$ isotropic voxels using a 12 parameter affine transformation and the PET template included in the SPM package; subsequently, the images were smoothed using an $8 \mathrm{~mm}$ isotropic Gaussian kernel. A full factorial design with group as between factor (NMLs vs HDs) and drug (PL and alcohol) and condition (NS and VS) as within factors was used to assess the following: (1) whether alcohol-induced metabolic changes differed between NML and HD when tested with NS and when tested with VS; and (2) whether alcohol effects differed between NS and VS. We also compared the resting metabolic measures (placebo NS) between HD and NML to assess whether these differed between groups. The model included two zero-mean covariates controlling for effects of gender and smoking, variables that were significantly different for NMLs and HDs. Significance was set as $p_{\mathrm{FWE}}<$ 0.05 corrected for multiple comparisons at the cluster level using the random field theory with a family wise error (FWE) correction, cluster forming threshold $p<0.005$ and a minimum cluster size of 100 voxels. In addition to assessing the regional effects from VS, we also used SPM to compare the relative metabolic images (normalized to whole brain) because relative measures increase the sensitivity to detect regional effects and significance set at $p_{\mathrm{FWE}}<0.05$. The measure of whole-brain metabolism was obtained by averaging the activity across the various axial planes in the brain.

\section{Results}

\section{Subject characteristics}

The groups differed in gender composition, 9 females in NML group and 0 females in HD group $(p=0.002)$, and in smoking histories, $7 \mathrm{HD}$ were current smokers, but 0 NML were smokers $(p=0.02)$. To account for the group differences in gender and smoking, we entered these two variables as covariates in the brain imaging comparisons between the groups.

As expected, the groups differed in average daily alcohol consumption (quantified as beer equivalents per day), which in NMLs was $0.26 \pm 0.5$ and in HDs was $8.6 \pm 3.4(p<0.0001)$.

\section{Plasma alcohol concentration, behavioral and cardiovascular effects}

Plasma alcohol concentration did not differ between NMLs and HDs or between the NS and VS conditions (Fig. 1A,B).

Alcohol increased self-reports of "high" (NS, $F=27, p<$ 0.0001 ; VS, $F=31, p<0.0001$ ), "intoxication" (NS, $F=125$, $p=$ 0.0001 ; VS, $F=72, p<0.0001$ ), and "desire for alcohol" (NS, $F=$ 

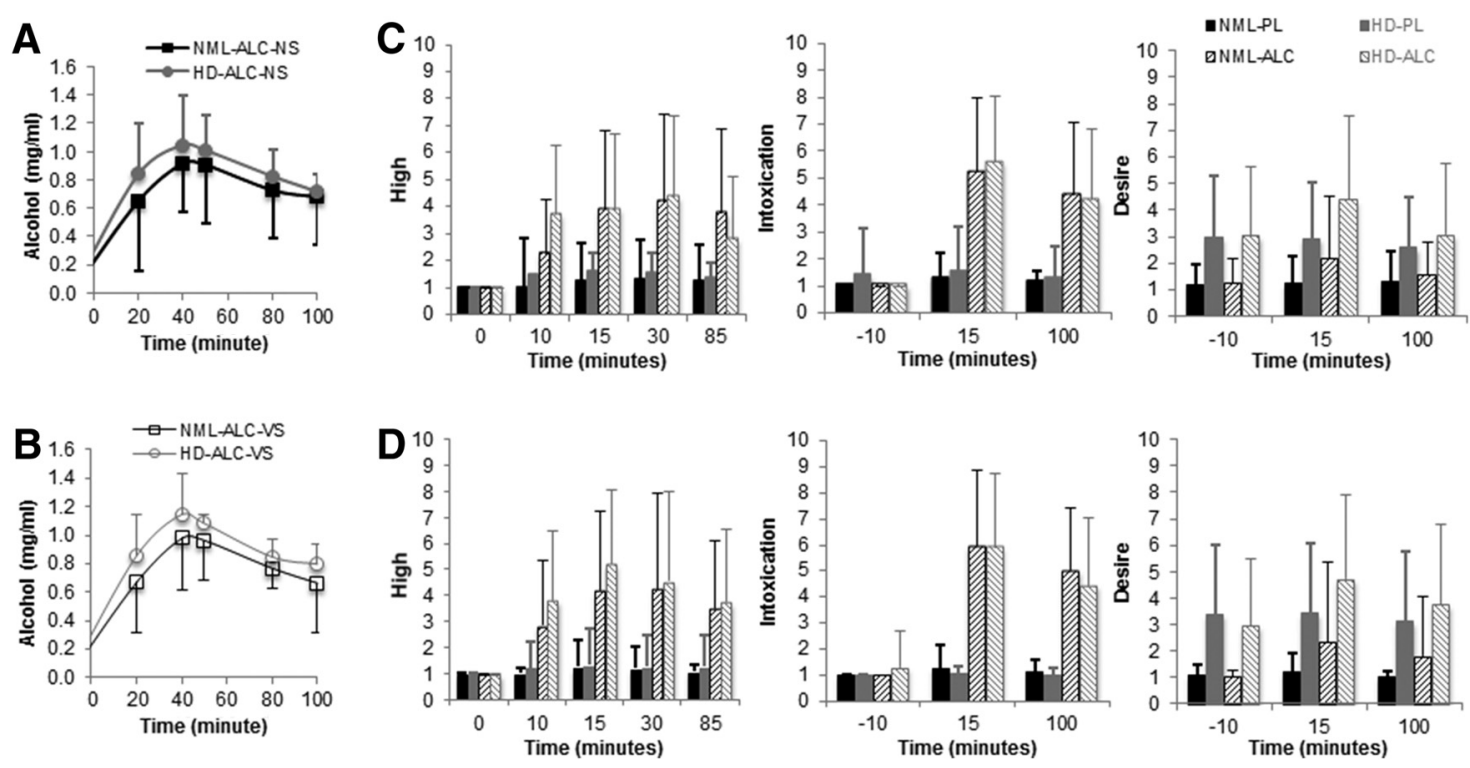

Figure 1. Alcohol levels in plasma and self-reports for drug effects after placebo (PL) and after alcohol (ALC) for the no-stimulation (NS) and for the video stimulation (VS) conditions in heavy drinkers (HD) and in normal controls (NML). Plasma alcohol concentration did not differ between NML and HD either for NS $(\boldsymbol{A})$ or VS (B). Alcohol significantly increased self-reports of high and intoxication both for NS ( $($ ) and VS (D) but did not increase desire for alcohol. The groups differed only on "Desire for alcohol", which was significantly higher for HD than NML (Cand $\boldsymbol{D}$, right). Alcohol behavioral effects did not differ between groups.

A

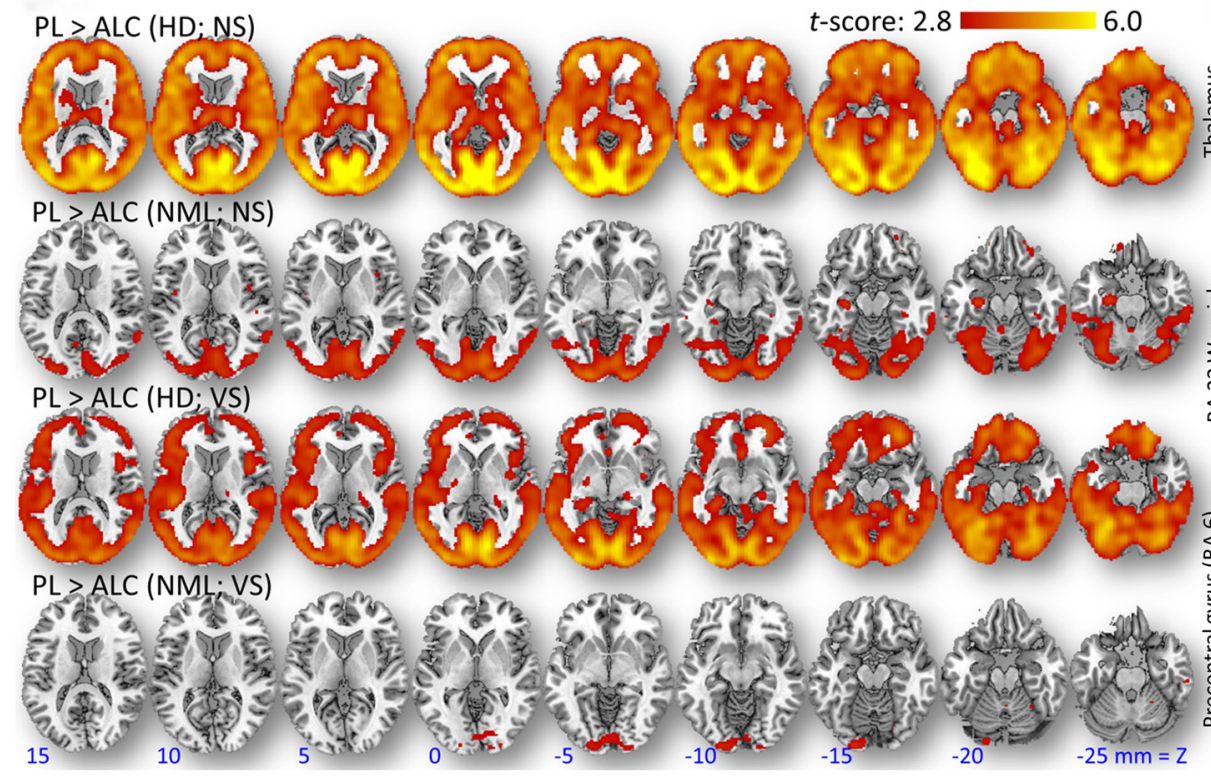

B
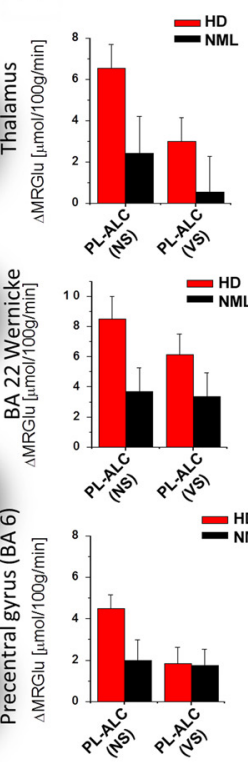

Figure 2. Effects of alcohol on brain glucose metabolism in NMLs and HDs. A,SPM results showing areas where the absolute metabolic measures were significantly reduced by alcohol compared with placebo (PL $>$ ALC) for the NS and the VS in NMLs and HDs at $p_{\mathrm{FWE}}<0.005$. B. Histogram showing regions where effects of alcohol where greater during NS than VS.

$5.1, p=0.008 ; \mathrm{VS}, F=7.7, p=0.0008)$. Alcohol-induced behavioral measures did not differ between groups (Fig. 1C,D). Across all time measures, "desire for alcohol" was higher for HD than NML (NS, $F=7.7 p=0.02$; VS, $F=6.8 p=0.02$ ).

\section{Effects of alcohol on brain glucose metabolism during NS} and VS

The SPM analysis $\left(p_{\mathrm{u}}<0.005\right)$ revealed that acute alcohol significantly decreased whole-brain glucose metabolism in NMLs and HDs for both NS and VS (Fig. 2; Table 1). The occipital cortex was the region that showed the largest decrements across both groups. Subcortical regions (striatum, thalamus, and midbrain) did not show significant decrements, except for the thalamus in HD (Fig. 2; Table 1). In both NMLs and HDs, alcohol-induced decrements in metabolism were more extensive for NS than for VS (Fig. 2).

The group $\times$ condition interaction was not significant for any of the brain regions, indicating that the effects of VS on alcoholinduced metabolic decrements did not differ between groups.

Plasma alcohol levels did not show significant correlation with alcohol-induced changes in brain glucose metabolism.

\section{Differences between NML and HD}

The SPM analysis assessing group differences in resting brain glucose metabolism (placebo-NS) showed that NMLs had signif- 
Table 1. SPM results for the differences between placebo (PL) and alcohol (ALC) ${ }^{a}$

\begin{tabular}{|c|c|c|c|c|c|c|c|c|}
\hline \multirow[b]{2}{*}{ Region } & \multirow[b]{2}{*}{ BA } & \multicolumn{3}{|c|}{ MNI coordinates, mm } & \multicolumn{2}{|c|}{$\begin{array}{l}\mathrm{PL}>\mathrm{ALC} \\
\text { (NS) } \\
\end{array}$} & \multicolumn{2}{|c|}{$\begin{array}{l}\mathrm{PL}>\mathrm{ALC} \\
\text { (VS) } \\
\end{array}$} \\
\hline & & $x$ & $y$ & $z$ & HD & NML & $H D$ & NML \\
\hline Calcarine & 17 & -8 & -82 & 0 & 7.2 & 3.7 & 5.6 & 2.3 \\
\hline Calcarine & 17 & 12 & -70 & 6 & 7.0 & 3.4 & 4.9 & 2.2 \\
\hline Cerebellum & & -40 & -64 & -40 & 6.8 & 3.8 & 4.1 & 2.6 \\
\hline Cerebellum & & -22 & -78 & -36 & 6.6 & 3.4 & 4.0 & 2.9 \\
\hline Vermis & & 6 & -70 & -36 & 6.6 & 3.1 & 4.2 & 2.4 \\
\hline Superior occipital & 18 & -20 & -90 & 22 & 6.3 & 3.0 & 4.1 & $\mathrm{NS}^{b}$ \\
\hline Cerebellum & & 36 & -72 & -22 & 6.1 & 3.8 & 5.3 & 2.2 \\
\hline Fusiform & 37 & 30 & -54 & -18 & 6.1 & 3.3 & 4.8 & 2.7 \\
\hline Middle occipital & 19 & -40 & -84 & 0 & 6.0 & 3.1 & 4.4 & 1.9 \\
\hline Inferior & 44 & -48 & 10 & 24 & 5.7 & 2.5 & 3.9 & 1.6 \\
\hline orbitofrontal & 11 & -18 & 38 & -22 & 5.6 & 2.5 & 4.1 & 2.2 \\
\hline Middle f & 47 & -38 & 46 & 0 & .4 & 2.2 & 3.3 & 1.8 \\
\hline Inferio & 20 & -52 & -10 & -26 & 5.3 & 2.1 & 3.8 & $\mathrm{NS}^{b}$ \\
\hline Inferior & 20 & 64 & -44 & -14 & 5.3 & 3.0 & 3.7 & 2.2 \\
\hline Middle c & 23 & 2 & -38 & 34 & .2 & 2.7 & 3.5 & 1.7 \\
\hline Middle oc & 39 & 48 & -74 & 24 & 5.2 & 2.6 & 3.7 & 1.9 \\
\hline tofrontal & 11 & 30 & 42 & -16 & 5.2 & 2.8 & 4.6 & 2.0 \\
\hline Inferic & 45 & 52 & 30 & 4 & 5.2 & 2.6 & 3.4 & 2.0 \\
\hline or temporal & 41 & -42 & -28 & 8 & 5.1 & 2.0 & 4.3 & $\mathrm{NS}^{b}$ \\
\hline rrginal & 42 & -58 & -24 & 18 & 5.1 & 1.7 & 3.3 & $\mathrm{NS}^{b}$ \\
\hline or frontal & 10 & -24 & 58 & 2 & 5.1 & 2.0 & 3.3 & 1.7 \\
\hline Angul & 7 & 38 & -74 & 40 & 5.1 & 2.8 & 3.5 & 2.4 \\
\hline frontal & 6 & 56 & 10 & 10 & 5.1 & 2.6 & 2.9 & 2.1 \\
\hline Superior frontal & 10 & 24 & 56 & 14 & 5.1 & 2.4 & 3.2 & 1.9 \\
\hline Angular & 39 & -50 & -62 & 24 & 5.1 & 2.1 & 3.8 & 1.7 \\
\hline Superior temporal & 22 & 52 & -24 & 8 & 5.1 & 2.6 & 3.6 & 1.9 \\
\hline Inferior temporal & 20 & 58 & -30 & -24 & 5.1 & 3.1 & 3.5 & 2.5 \\
\hline Precentral & 44 & 48 & 6 & 34 & 5.0 & 2.7 & 3.7 & 2.0 \\
\hline Superior temporal & 42 & -54 & -42 & 18 & 5.0 & 2.2 & 3.2 & $\mathrm{NS}^{b}$ \\
\hline Middle frontal & 9 & -30 & 40 & 36 & 5.0 & NS & 2.5 & $\mathrm{NS}^{b}$ \\
\hline Inferior parietal & 3 & -52 & -26 & 50 & 4.7 & 1.9 & 2.4 & $\mathrm{NS}^{b}$ \\
\hline Precentral & 6 & -36 & 2 & 56 & 4.7 & 2.0 & 3.0 & $\mathrm{NS}^{b}$ \\
\hline Middle cingulum & 32 & 8 & 36 & 30 & 4.5 & 2.0 & 2.6 & $\mathrm{NS}^{b}$ \\
\hline Middle frontal & 8 & -24 & 12 & 56 & 4.4 & 1.9 & 2.9 & $\mathrm{NS}^{b}$ \\
\hline Precentral & 6 & 38 & -8 & 56 & 4.3 & 1.7 & 2.6 & $\mathrm{NS}^{b}$ \\
\hline Thalamus & 0 & 14 & -18 & 8 & 4.3 & NS & 2.7 & $\mathrm{NS}^{b}$ \\
\hline
\end{tabular}

${ }^{a}$ Data represent statistical significance ( $t$-score) and the spatial location of the clusters showing significant differences in absolute glucose metabolism between placebo (PL) and alcohol (ALC) conditions under VS and NS for HDS and NMLs.

${ }^{b} \mathrm{NS}$, Not significant.

icantly higher metabolism than HDs (Fig. 3). Whole-brain metabolic values corresponded for the NMLs to $38.6 \pm 6 \mu \mathrm{mol} / 100$ $\mathrm{g} / \mathrm{min}$ and for the HDs to $33.6 \pm 6 \mu \mathrm{mol} / 100 \mathrm{~g} / \mathrm{min}$ (group difference, $p<0.01$ ).

The SPM analysis to assess group differences in alcohol effects showed that alcohol-induced metabolic decreases were more extensive in HDs than in NMLs and were larger in thalamus, frontal, and temporal cortices in HDs than NMLs (Fig. 2). Whole-brain metabolism was reduced by alcohol during NS by $9.3 \pm 11 \%$ (change from placebo) in NMLs and $19.8 \pm 13 \%$ (group difference, $p<0.005$ ) in HDs; and during VS, it was reduced by $6.1 \pm 13 \%$ in NMLs and $13.6 \pm 12 \%$ in HDs (group difference, $p<0.05$ ).

Daily alcohol consumption showed significant correlation with the decreases in whole-brain glucose metabolism for NS $(r=0.42, p=0.003)$ and a trend for VS $(r=0.27, p=0.06)$.

\section{Effect of alcohol on VS-induced increases in visual cortical metabolism}

Because the effect of VS on brain glucose metabolism was not significantly different between HDs and NMLs in any brain region we combined both groups to increase statistical power.
Video stimulation (VS vs NS) increased glucose metabolism in the visual cortex (BA 18) during placebo and in visual (BA 18) and auditory (left BA 22) cortices during alcohol intoxication (Fig. 4; Table 2). Although the effects of VS in the visual cortex tended to be larger during alcohol intoxication than during placebo, this effect was not significant after correction for multiple comparisons.

To assess the effects of VS on regional brain metabolism, we also computed its effects on the "relative" metabolic images (normalized to whole-brain metabolism) to enhance regional over global effects. SPM on the "relative" metabolic images revealed significant VS-induced increases in visual and auditory cortices both during placebo and during alcohol intoxication (Fig. 5). There were no differences on VS-induced increases in "relative" metabolism between placebo and alcohol intoxication.

\section{Discussion}

Here we show the following: (1) a marked decrease in brain glucose metabolism during alcohol intoxication that was significantly greater in HDs than NMLs; (2) alcohol intoxication, despite inducing marked decrements in whole-brain glucose metabolism during rest, did not reduce increases in regional glucose metabolism during stimulation (VS); and (3) VS reduced the magnitude of the decrements in brain glucose metabolism induced by alcohol intoxication. We also show that resting brain glucose metabolism was significantly lower for HDs than for NMLs.

\section{Alcohol-induced decreases in brain glucose metabolism were larger for HD than for NML}

The reductions in brain glucose metabolism during alcohol intoxication corroborate prior findings of decrements in brain glucose metabolism during intoxication that as for the current study were largest in occipital cortex and smallest in subcortical brain regions (for review, see Volkow et al., 2006), including our recent findings showing an opposite pattern between the regional increases in acetate metabolism and the regional decreases in brain glucose metabolism (Volkow et al., 2013). Our findings of significantly larger brain metabolic decrements with alcohol intoxication in HDs than in NMLs are consistent with our pilot study that reported significantly larger reductions in brain glucose metabolism with alcohol in alcoholics $(n=6)$ than in controls $(n=6)$ despite alcoholics being less intoxicated than the controls (Volkow et al., 1990).

Alcohol-induced reductions in brain glucose metabolism could reflect either the GABAergic-enhancing effects of alcohol (Wang et al., 2000; Roberto et al., 2003; Rae et al., 2014) and/or the use of acetate (or other ketone bodies) as an alternative energy substrate during intoxication (Pawlosky et al., 2010). Our current findings suggest that they reflect the use of an alternative energy source. First, the higher metabolic reduction in HD than in NML is compatible with the use of alternative energy sources during intoxication because alcohol abusers show attenuated reductions in brain glucose metabolism when given GABAergic-enhancing drugs (Volkow et al., 1993, 1997) rather than an enhanced reduction as shown here. Second, the lower sensitivity to alcoholinduced metabolic decreases in the thalamus, which was also the region that had the smallest increases in acetate metabolism during intoxication (Volkow et al., 2013) but the most sensitive to the decrements in glucose metabolism triggered by GABAergicenhancing drugs (Volkow et al., 1995), is also consistent with alcohol-induced use of acetate as an alternate energy substrate. The thalamus might have been the least sensitive region to the 

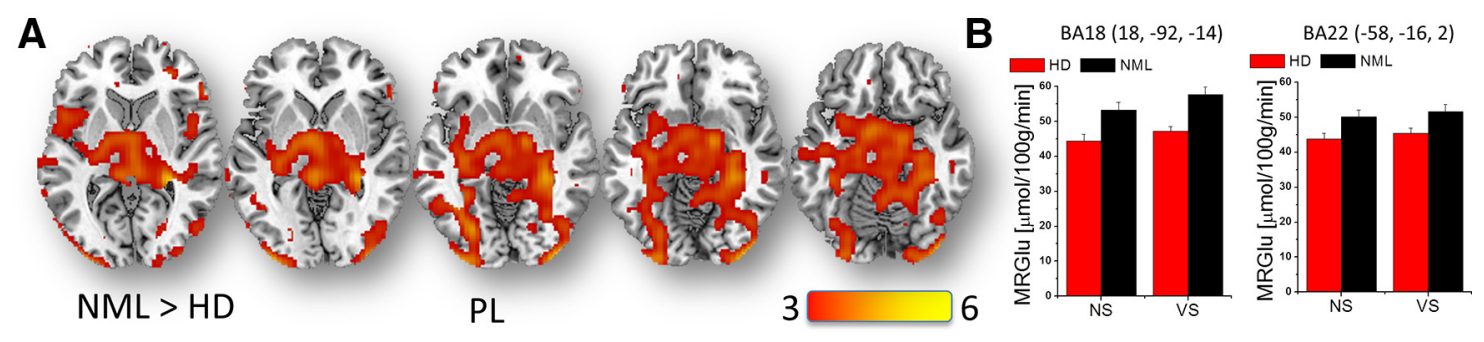

Figure 3. Differences in baseline brain glucose metabolism (placebo measures) between NMLs and HDs. $A$, SPM results showing areas where metabolism was significantly greater for NMLs than $\mathrm{HDs}\left(\mathrm{NML}>\mathrm{HD}\right.$ ) at $p_{\mathrm{FWE}}<0.0001$. B, Histogram showing brain metabolism in BA 18 and BA 22 for the placebo conditions; these areas also showed greater metabolic values in NMLs than HDs.
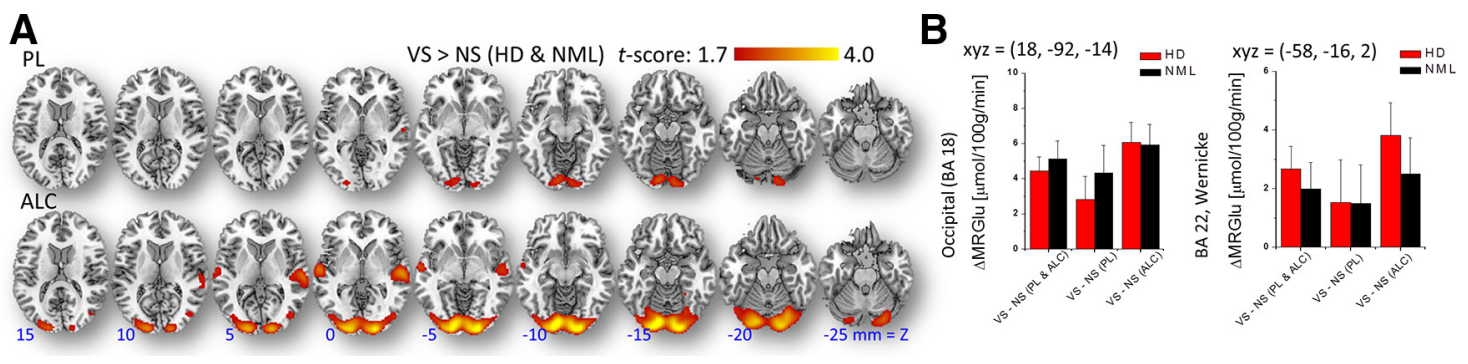

Figure 4. Effects of VS on brain glucose metabolism (absolute metabolic images) compared with NS during placebo (PL) and alcohol intoxication (ALC). $A$, SPM results showing areas where metabolism was greater for VS $>$ NS for significance $p_{\mathrm{FWE}}<0.05$. There were no areas where metabolism was greater for NS than for VS. $\boldsymbol{B}$, Histograms showing the differences (VS vs NS) in metabolic rates in BA 18 and BA 22, for the combined PL and ALC for NMLs and HDs.

Table 2. SPM results for comparison on brain glucose metabolism between VS and $\mathrm{NS}^{a}$

\begin{tabular}{|c|c|c|c|c|c|c|}
\hline \multirow[b]{2}{*}{ Region } & \multirow[b]{2}{*}{ BA } & \multicolumn{3}{|c|}{ MNI coordinates, mm } & \multicolumn{2}{|c|}{ VS $>N S$} \\
\hline & & $x$ & $y$ & $z$ & $\overline{\mathrm{ALC}}$ & $P L$ \\
\hline Lingual & 18 & 14 & -90 & -12 & 4.5 & 2.3 \\
\hline Inferior occipital & 18 & -20 & -96 & -6 & 4.3 & 1.8 \\
\hline Superior temporal & 22 & -58 & -20 & 2 & 3.0 & 1.8 \\
\hline Superior temporal & 22 & 60 & -12 & 0 & 2.7 & $\mathrm{NS}{ }^{b}$ \\
\hline
\end{tabular}

${ }^{a}$ Data represent the statistical significance ( $t$-score) and spatial location of the clusters showing significant differences in absolute glucose metabolism between VS and NS, for alcohol (ALC) and placebo (PL) conditions, across all subjects (NML and HD conjunction analysis).

${ }^{b} \mathrm{NS}$, Not significant.

effects of alcohol in glucose and acetate metabolism because the expression of monocarboxylic acid transporters, which transport acetate into asytrocytes (Pellerin et al., 1998) and the levels of acetyl-CoA synthetase, which is an enzyme needed for acetate oxidation, are low (Qin and Crew, 2014). Thus, our findings are consistent with the hypothesis that the reduction in brain glucose metabolism during intoxication is due to increased metabolism of alternative energy substrates (presumably acetate) and that chronic alcohol exposure facilitates this shift.

Acetate is readily taken up by the brain and metabolized by glia (Cruz et al., 2005). Under normal physiological conditions, plasma acetate levels are low $(\sim 0.2-0.3 \mathrm{~mm})$, but during intoxication the blood concentration of acetate increases $(\sim 1 \mathrm{~mm})$ (Orrego et al., 1988) to levels that could support 10\%-20\% of total brain metabolic rate (Waniewski and Martin, 1998). Moreover, during intoxication, the blood acetate concentrations are higher for alcoholics than for controls (Nuutinen et al., 1985), which could facilitate metabolism of acetate by glial cells, as shown for laboratory animals chronically exposed to alcohol (Wang et al., 2013a, b). Figure 6 summarizes the interpretation of our findings.

Although we interpret the enhanced reduction in glucose metabolism during intoxication in HDs to reflect a priming for their metabolism of acetate, in a prior study in which we reported increases in brain acetate metabolism during intoxication (measured with $\left[{ }^{11} \mathrm{C}\right]$ acetate and PET), we showed no differences in alcohol-induced increases in acetate metabolism between controls and HDs (Volkow et al., 2013). However, brain acetate metabolism in the HDs tended to be higher than in controls, particularly for the scans taken during intoxication, and was associated with their alcohol histories, consistent with priming for the use of acetate as brain energy substrate in HDs (Volkow et al., 2013). Alternatively, the discrepancy between the current and our prior study could indicate that acetate might not be the only alternative energy substrate used by the brain during intoxication.

\section{Alcohol did not reduce glucose metabolic increases in visual cortex from video-stimulation}

Despite the marked reductions in brain glucose metabolism during intoxication, the increases in glucose metabolism in visual cortex (and auditory cortex) triggered by VS were not decreased by alcohol compared with placebo. This indicates that the increased energy required by the stimulation is dependent on glucose.

Indeed, stimulations that increase energy demand require additional increases in glucose metabolism by neurons and glia (Kasischke et al., 2004). Furthermore, there is evidence that taskinduced changes in regional brain activity are associated with increases in aerobic glycolysis (glucose utilization that is in excess of its use for oxidative phosphorylation despite sufficient oxygen) (Fox et al., 1988; Vlassenko et al., 2006), which could account in part for the reliance on glucose during brain stimulation. Intriguingly, there is also evidence of generation of ATP through glycolytic metabolism in dendritic spines during synaptic signaling that might also underlie the need of glucose from brain stimulation (Wu et al., 1997).

\section{VS attenuated alcohol-induced decrements in brain glucose metabolism}

The attenuated effects of alcohol during VS are consistent with the preferential upregulation of glycolysis during activation 
A

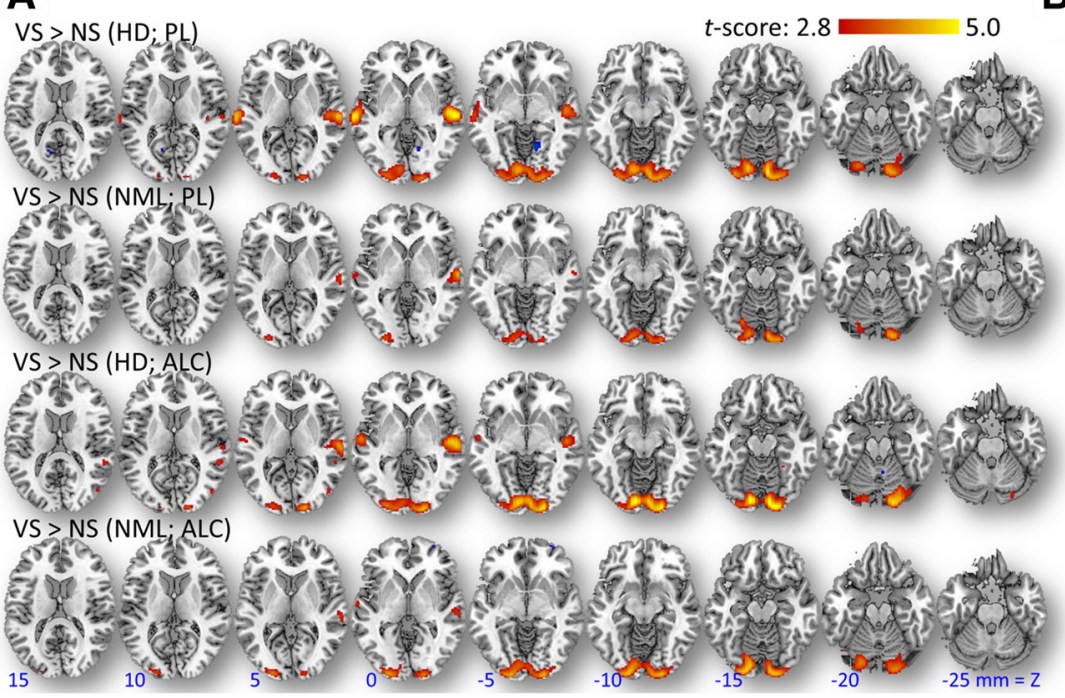

B

$\operatorname{BA} 18(18,-92,-14)$

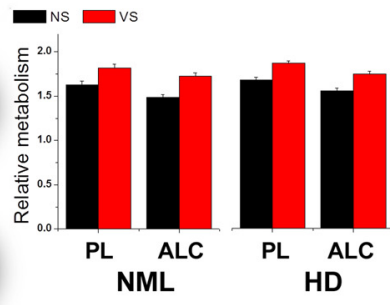

BA22 $(-58,-16,2)$

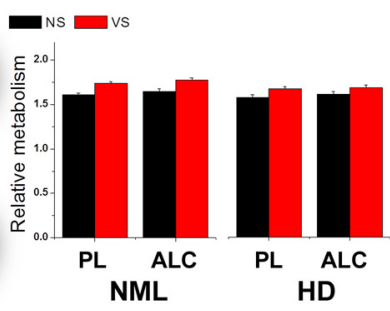

Figure 5. Effects of VS on relative metabolic images (normalized to whole-brain metabolism) during placebo (PL) and alcohol intoxication (ALC). A, SPM results showing areas where "relative metabolism" was greater for VS $>$ NS for significance $p_{\mathrm{FWE}}<0.05$. B, Histograms showing "relative" metabolic values in BA 18 and BA 22 , for NMLs and for HDs, during the PL and ALC conditions.
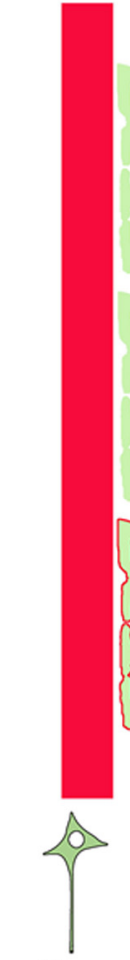

Neuron Oxidative Phosphorylation

\section{SOBRIETY}
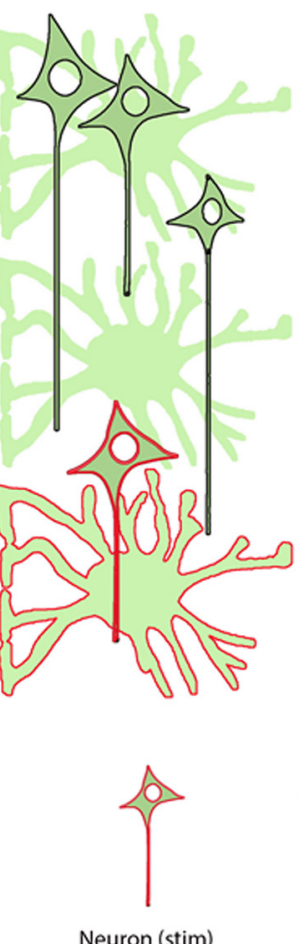

euron (stim)

Aerobic
Glycolysis

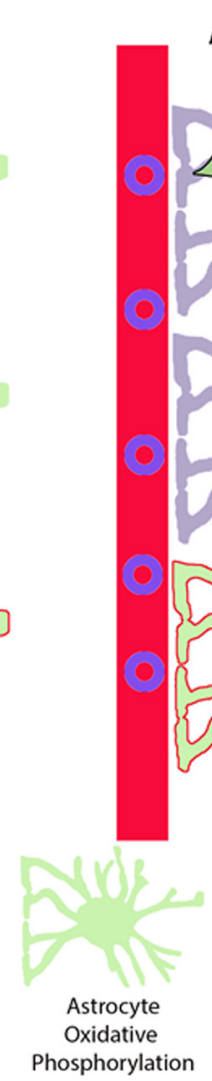

ACUTE ALCOHOL
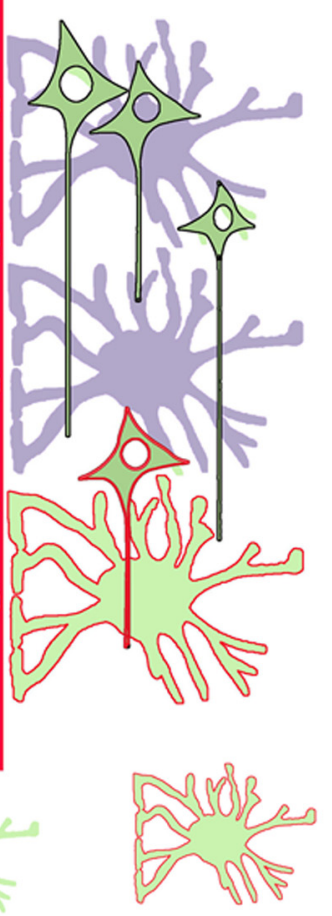

Astrocyte (stim)

Aerobic

Glycolysis

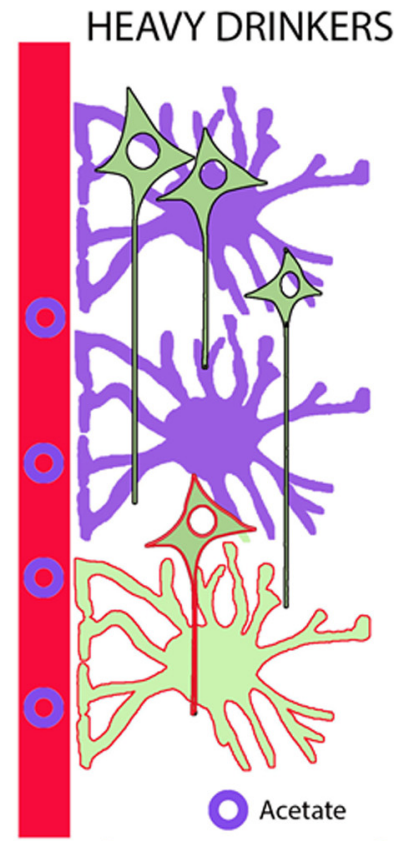

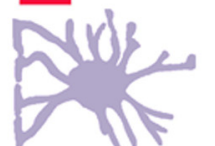

Astrocyte oxidizing acetate

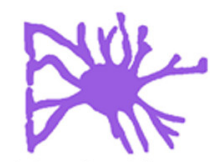

Astrocyte relying on acetate for energy

Figure 6. Simplified model for the interpretation of our findings. In sobriety, glia and neurons predominantly rely on glucose as energy substrate for metabolism at rest and during stimulation, both through aerobic glycolysis and through oxidative phosphorylation. During alcohol intoxication (acute alcohol), when acetate levels in plasma increase, glial cells increase their reliance on acetate metabolism as energy source to sustain resting activity. In HDs, the reliance of glial cells on acetate to sustain resting activity is enhanced and persists beyond intoxication, which could contribute to their low resting brain glucose metabolic rates during sobriety but also their larger decrements in brain glucose metabolism during intoxication.

(Dienel et al., 2001). The fact that during stimulation neurons require immediate access to glucose, which is predominantly processed through the anaerobic cycle, could explain why we observed an attenuation of alcohol-induced decrements in brain glucose metabolism during the VS condition.
Brain glucose metabolism at baseline (placebo-NS) was lower in HD than NML

The lower brain glucose metabolism in the HD compared with NML (placebo-NS) is consistent with the findings that alcoholics have significant reductions in brain glucose metabolism com- 
pared with healthy controls (Samson et al., 1986; Gilman et al., 1990; Martin et al., 1992; Volkow et al., 1992; Adams et al., 1993; Wang et al., 1993). Although the reductions in regional brain glucose metabolism in alcoholics could reflect neurotoxicity, these reductions have also been reported in neurologically intact healthy alcoholics (Volkow et al., 1992), indicating that they could also reflect reliance on alternative energy substrates for brain metabolism. Because most findings are derived from testing alcoholics during early detoxification, they suggest that reliance on alternative energy substrates for brain metabolism may persist after intoxication has subsided. Indeed, a recent MRS study showed significantly enhanced acetate metabolism in the occipital cortex of HDs studied during sobriety (Jiang et al., 2013). Persistent reliance on brain acetate metabolism for energetics during early alcohol detoxification could also explain why reductions in brain glucose metabolism in alcoholics mostly recover within the first 2 weeks of detoxification (Volkow et al., 1994) and why female alcoholics who were studied on average $30 \mathrm{~d}$ after detoxification showed no abnormalities in brain glucose metabolism (Wang et al., 1998).

\section{Clinical implications}

Our current findings, along with those from prior studies (Jiang et al., 2013; Volkow et al., 2013; Wang et al., 2013b), indicate that with chronic alcohol exposure the brain increasingly relies on acetate for metabolism. This is likely to have clinical implications for the management of alcohol use disorders. Specifically, during acute alcohol withdrawal, the associated drop in acetate plasma levels might result in a sudden deprivation of a favored energy substrate that could result in brain energy deprivation and contribute to the adverse effects of alcohol withdrawal in alcohol abusers. Indeed, energy deprivation had previously been proposed to contribute to the emergence of alcohol withdrawal during alcohol discontinuation (Derr, 1984); and in rodents, acetate infusion abated the signs of ethanol withdrawal (Derr et al., 1981). This raises the possibility that a ketogenic diet by providing a high level of acetone could help minimize adverse effects from acute alcohol withdrawal in alcohol abusers undergoing detoxification.

\section{Limitations}

It would have been desirable to measure plasma acetate concentrations both at baseline and during intoxication, which would have allowed us to assess whether the lower baseline brain metabolic measures in the HD reflected higher plasma acetate levels and to assess the correlations between alcohol-induced increases in plasma acetate levels during intoxication and the reductions in brain glucose metabolism. Future mechanistic studies, including these measures, merit consideration.

In conclusion, we show that alcohol markedly reduces brain glucose metabolism at baseline but does not interfere with the increases in metabolism from activation, which indicates that the shift in alternative energy substrates relates to resting activity only (presumably glia support of baseline activity) and not to energy requirements for stimulation (presumably glucose to support neuronal and glial activation). We also show that HDs have an enhanced reduction in glucose metabolism with alcohol intoxication consistent with their brain being more adept at using alternative energy substrates (presumably acetate) secondary to chronic alcohol exposures.

\section{References}

Adams KM, Gilman S, Koeppe RA, Kluin KJ, Brunberg JA, Dede D, Berent S, Kroll PD (1993) Neuropsychological deficits are correlated with frontal hypometabolism in positron emission tomography studies of older alcoholic patients. Alcohol Clin Exp Res 17:205-210. CrossRef Medline

Cruz NF, Lasater A, Zielke HR, Dienel GA (2005) Activation of astrocytes in brain of conscious rats during acoustic stimulation: acetate utilization in working brain. J Neurochem 92:934-947. CrossRef Medline

Derr RF (1984) The ethanol withdrawal syndrome: a consequence of lack of substrate for a cerebral Krebs-cycle. J Theor Biol 106:375-381. CrossRef Medline

Derr RF, Draves K, Derr M (1981) Abatement by acetate of an ethanol withdrawal syndrome. Life Sci 29:1787-1790. CrossRef Medline

de Wit H, Metz J, Wagner N, Cooper M (1990) Behavioral and subjective effects of ethanol: relationship to cerebral metabolism using PET. Alcohol Clin Exp Res 14:482-489. CrossRef Medline

Dienel GA, Popp D, Drew PD, Ball K, Krisht A, Cruz NF (2001) Preferential labeling of glial and meningial brain tumors with [2-(14)C]acetate. J Nucl Med 42:1243-1250. Medline

Fox PT, Raichle ME, Mintun MA, Dence C (1988) Nonoxidative glucose consumption during focal physiologic neural activity. Science 241:462464. CrossRef Medline

Friston KJ, Holmes AP, Poline JB, Grasby PJ, Williams SC, Frackowiak RS, Turner R (1995) Analysis of fMRI time-series revisited. Neuroimage 2:45-53. CrossRef Medline

Gilman S, Adams K, Koeppe RA, Berent S, Kluin KJ, Modell JG, Kroll P, Brunberg JA (1990) Cerebellar and frontal hypometabolism in alcoholic cerebellar degeneration studied with positron emission tomography. Ann Neurol 28:775-785. CrossRef Medline

Hetherington HP, Telang F, Pan JW, Sammi M, Schuhlein D, Molina P, Volkow ND (1999) Spectroscopic imaging of the uptake kinetics of human brain ethanol. Magn Reson Med 42:1019-1026. CrossRef Medline

Jiang L, Gulanski BI, De Feyter HM, Weinzimer SA, Pittman B, Guidone E, Koretski J, Harman S, Petrakis IL, Krystal JH, Mason GF (2013) Increased brain uptake and oxidation of acetate in heavy drinkers. J Clin Invest 123:1605-1614. CrossRef Medline

Kasischke KA, Vishwasrao HD, Fisher PJ, Zipfel WR, Webb WW (2004) Neural activity triggers neuronal oxidative metabolism followed by astrocytic glycolysis. Science 305:99-103. CrossRef Medline

Lloyd B, Burrin J, Smythe P, Alberti KG (1978) Enzymic fluorometric continuous-flow assays for blood glucose, lactate, pyruvate, alanine, glycerol, and 3-hydroxybutyrate. Clin Chem 24:1724-1729. Medline

Martin PR, Rio D, Adinoff B, Johnson JL, Bisserbe JC, Rawlings RR, Rohrbaugh JW, Stapleton JM, Eckardt MJ (1992) Regional cerebral glucose utilization in chronic organic mental disorders associated with alcoholism. J Neuropsychiatry Clin Neurosci 4:159-167. CrossRef Medline

Nuutinen H, Lindros K, Hekali P, Salaspuro M (1985) Elevated blood acetate as indicator of fast ethanol elimination in chronic alcoholics. Alcohol 2:623-626. CrossRef Medline

Orrego H, Carmichael FJ, Israel Y (1988) New insights on the mechanism of the alcohol-induced increase in portal blood flow. Can J Physiol Pharmacol 66:1-9. CrossRef Medline

Pawlosky RJ, Kashiwaya Y, Srivastava S, King MT, Crutchfield C, Volkow N, Kunos G, Li TK, Veech RL (2010) Alterations in brain glucose utilization accompanying elevations in blood ethanol and acetate concentrations in the rat. Alcohol Clin Exp Res 34:375-381. CrossRef Medline

Pellerin L, Pellegri G, Martin JL, Magistretti PJ (1998) Expression of monocarboxylate transporter mRNAs in mouse brain: support for a distinct role of lactate as an energy substrate for the neonatal vs. adult brain. Proc Natl Acad Sci U S A 95:3990-3995. CrossRef Medline

Phelps ME, Huang SC, Hoffman EJ, Selin C, Sokoloff L, Kuhl DE (1979) Tomographic measurement of local cerebral glucose metabolic rate in humans with (F-18)2-fluoro-2-deoxy-D-glucose: validation of method. Ann Neurol 6:371-388. CrossRef Medline

Qin L, Crews FT (2014) Focal thalamic degeneration from ethanol and thiamine deficiency is associated with neuroimmune gene induction, microglial activation, and lack of monocarboxylic acid transporters. Alcohol Clin Exp Res 38:657-671. CrossRef Medline

Rae CD, Davidson JE, Maher AD, Rowlands BD, Kashem MA, Nasrallah FA, Rallapalli SK, Cook JM, Balcar VJ (2014) Ethanol, not detectably metabolized in brain, significantly reduces brain metabolism, probably via action at specific $\mathrm{GABA}(\mathrm{A})$ receptors and has measureable metabolic effects at very low concentrations. J Neurochem 129:304-314. CrossRef Medline

Roberto M, Madamba SG, Moore SD, Tallent MK, Siggins GR (2003) Ethanol increases GABAergic transmission at both pre- and postsynaptic sites 
in rat central amygdala neurons. Proc Natl Acad Sci U S A 100:20532058. CrossRef Medline

SAMHSA (2012a) Substance Abuse and Mental Health Services Administration (SAMHSA). 2012 National Survey on Drug Use and Health (NSDUH). Available at: http://www.samhsa.gov/data/NSDUH/2012SummNatFindDetTables/DetTabs/NSDUH-DetTabsSect2peTabs43to84 -2012.htm\#Tab2.71B.

SAMHSA (2012b) Substance Abuse and Mental Health Services Administration (SAMHSA). 2012 National Survey on Drug Use and Health (NSDUH). Available at: http://www.samhsa.gov/data/NSDUH/2012SummNatFindDetTables/DetTabs/NSDUH-DetTabsSect2peTabs43to84 -2012.htm\#Tab2.46B.

Samson Y, Baron JC, Feline A, Bories J, Crouzel C (1986) Local cerebral glucose utilisation in chronic alcoholics: a positron tomographic study. J Neurol Neurosurg Psychiatry 49:1165-1170. CrossRef Medline

Schreckenberger M, Amberg R, Scheurich A, Lochmann M, Tichy W, Klega A, Siessmeier T, Gründer G, Buchholz HG, Landvogt C, Stauss J, Mann K, Bartenstein P, Urban R (2004) Acute alcohol effects on neuronal and attentional processing: striatal reward system and inhibitory sensory interactions under acute ethanol challenge. Neuropsychopharmacology 29: 1527-1537. CrossRef Medline

Stinson F, Yi H, Grant B, Chou P, Dawson D, Pickering R (1998) Drinking in the United States: main findings from the 1992 National Longitudinal Alcohol Epidemiologic Survey (NLAES). U.S. alcohol epidemiologic data reference manual, Ed 1, Vol 6, November 1998, NIH Publication No. 99-3519. Bethesda, MD.

Vlassenko AG, Rundle MM, Mintun MA (2006) Human brain glucose metabolism may evolve during activation: findings from a modified FDG PET paradigm. Neuroimage 33:1036-1041. CrossRef Medline

Volkow ND, Hitzemann R, Wolf AP, Logan J, Fowler JS, Christman D, Dewey SL, Schlyer D, Burr G, Vitkun S, et al. (1990) Acute effects of ethanol on regional brain glucose metabolism and transport. Psychiatr Res 35:39-48. CrossRef Medline

Volkow ND, Hitzemann R, Wang GJ, Fowler JS, Burr G, Pascani K, Dewey SL, Wolf AP (1992) Decreased brain metabolism in neurologically intact healthy alcoholics. J Psychiatry 149:1016-1022. Medline

Volkow ND, Wang GJ, Hitzemann R, Fowler JS, Wolf AP, Pappas N, Biegon A, Dewey SL (1993) Decreased cerebral response to inhibitory neurotransmission in alcoholics. J Psychiatry 150:417-422. Medline

Volkow ND, Wang GJ, Hitzemann R, Fowler JS, Overall JE, Burr G, Wolf AP (1994) Recovery of brain glucose metabolism in detoxified alcoholics. J Psychiatry 151:178-183. Medline
Volkow ND, Wang GJ, Hitzemann R, Fowler JS, Pappas N, Lowrimore P, Burr G, Pascani K, Overall J, Wolf AP (1995) Depression of thalamic metabolism by lorazepam is associated with sleepiness. Neuropsychopharmacology 12:123-132. CrossRef Medline

Volkow ND, Wang GJ, Overall JE, Hitzemann R, Fowler JS, Pappas N, Frecska E, Piscani K (1997) Regional brain metabolic response to lorazepam in alcoholics during early and late alcohol detoxification. Alcohol Clin Exp Res 21:1278-1284. CrossRef Medline

Volkow ND, Wang GJ, Franceschi D, Fowler JS, Thanos PP, Maynard L, Gatley SJ, Wong C, Veech RL, Kunos G, Kai Li T (2006) Low doses of alcohol substantially decrease glucose metabolism in the human brain. Neuroimage 29:295-301. CrossRef Medline

Volkow ND, Kim SW, Wang GJ, Alexoff D, Logan J, Muench L, Shea C, Telang F, Fowler JS, Wong C, Benveniste H, Tomasi D (2013) Acute alcohol intoxication decreases glucose metabolism but increases acetate uptake in the human brain. Neuroimage 64:277-283. CrossRef Medline

Wang GJ, Volkow ND, Roque CT, Cestaro VL, Hitzemann RJ, Cantos EL, Levy AV, Dhawan AP (1993) Functional importance of ventricular enlargement and cortical atrophy in healthy subjects and alcoholics as assessed with PET, MR imaging, and neuropsychologic testing. Radiology 186:59-65. CrossRef Medline

Wang GJ, Volkow ND, Fowler JS, Pappas NR, Wong CT, Pascani K, Felder CA, Hitzemann RJ (1998) Regional cerebral metabolism in female alcoholics of moderate severity does not differ from that of controls. Alcohol Clin Exp Res 22:1850-1854. CrossRef Medline

Wang GJ, Volkow ND, Franceschi D, Fowler JS, Thanos PK, Scherbaum N, Pappas N, Wong CT, Hitzemann RJ, Felder CA (2000) Regional brain metabolism during alcohol intoxication. Alcohol Clin Exp Res 24:822829. CrossRef Medline

Wang J, Du H, Jiang L, Ma X, de Graaf RA, Behar KL, Mason GF (2013a) Oxidation of ethanol in the rat brain and effects associated with chronic ethanol exposure. Proc Natl Acad Sci U S A 110:14444-14449. CrossRef Medline

Wang J, Du H, Ma X, Pittman B, Castracane L, Li TK, Behar KL, Mason GF (2013b) Metabolic products of [2-(13) C]ethanol in the rat brain after chronic ethanol exposure. J Neurochem 127:353-364. CrossRef Medline

Waniewski RA, Martin DL (1998) Preferential utilization of acetate by astrocytes is attributable to transport. J Neurosci 18:5225-5233. Medline

Wu K, Aoki C, Elste A, Rogalski-Wilk AA, Siekevitz P (1997) The synthesis of ATP by glycolytic enzymes in the postsynaptic density and the effect of endogenously generated nitric oxide. Proc Natl Acad Sci U S A 94:1327313278. CrossRef Medline 